ARTICLE

Received 26 Sep 2015 | Accepted 29 Mar 2016 | Published 17 May 2016

DOI: $10.1057 /$ palcomms.2016.13

OPEN

\title{
Quantifying the economic impact of changes in energy demand for space heating and cooling systems under varying climatic scenarios
}

Tomoko Hasegawa ${ }^{1}$, Chan Park ${ }^{2}$, Shinichiro Fujimori ${ }^{1}$, Kiyoshi Takahashi ${ }^{1}$, Yasuaki Hijioka ${ }^{1}$ and Toshihiko Masui $^{1}$

\begin{abstract}
The building sector is highly sensitive to climate change, where energy is used for numerous purposes such as heating, cooling, cooking and lighting. Space heating and cooling account for a large proportion of overall energy use, and the associated energy demand is also affected by climate change. Here, we project the economic impact of changes in energy demand for space heating and cooling under multiple climatic conditions. We use an economic model coupled with an end-use technology model to explicitly represent the investment costs for air-conditioning technologies, which influence the macroeconomy. We conclude that the negative effects on the economy from increases in the use of space cooling are sufficiently large to neutralize the positive impacts from reductions in space heating usage under climate change, which results in significant economic loss. The economic loss under the highest emissions scenario (RCP8.5) would correspond to a $-0.34 \%(-0.39 \%$ to $-0.18 \%$ ) change in global gross domestic product (GDP) in 2100 compared with GDP without any climate change, while the impact under the lowest emissions scenario (RCP2.6) would result in a $-0.03 \%(-0.07 \%$ to $-0.01 \%)$ change in global GDP in 2100 . The economic losses are mainly generated by incremental technological costs and not by changes in energy demand itself. The amount of economic loss can vary substantially based on assumptions of technological costs, population and income. To reduce the negative impacts of climate change measures for reducing the costs of air conditioning will be an important consideration for the building sector in the future.
\end{abstract}

\footnotetext{
${ }^{1}$ Center for Social \& Environmental Systems Research, National Institute for Environmental Studies, Tsukuba, Japan ${ }^{2}$ Department of Landscape Architecture, College of Urban Science, University of Seoul, Seoul, Korea Correspondence: (e-mails: hasegawa.tomoko@nies.go.jp; chaneparkmomo7@uos.ac.kr)
} 


\section{Introduction}

- he energy sector is strongly affected by climate change (Arent et al., 2014). On the supply side, water cooling systems are required for thermal power plants, and water availability is affected by changes in precipitation. Solar and wind power also depend on climatic conditions. On the demand side, the building sector is highly sensitive to climate change, where energy is used for numerous purposes such as heating, cooling, cooking and lighting. Space heating and cooling account for a large proportion of overall energy use, and the associated energy demand is also affected by climate change (Mideksa and Kallbekken, 2010).

Several recent studies have assessed the impact of climate change on energy demand for space heating and cooling. These studies can be divided into three categories (Ciscar and Dowling, 2014): (1) assessments of the statistical relationship between climatic conditions and energy variables (De Cian et al., 2013); (2) incorporation of empirical results into broader modelling systems (Isaac and van Vuuren, 2009; Mima and Criqui, 2009; Roson and van der Mensbrugghe, 2012); and (3) integration of technological choices into broader modelling systems (Eom et al., 2012; Zhou et al., 2014). Most studies agree that the effect of climate change on global energy use is miniscule, as decreases in heating are counteracted by increases in cooling. However, the limited impact of climate change on global energy may have a much greater effect on the economy because the economic impact of fluctuations in energy use depends on energy systems and/or industrial structures.

With respect to the economic impact of changes in energy demand, some studies have assessed the potential changes in gross domestic product (GDP) related to changes in demand for spatial heating and cooling (Eboli et al., 2010; Bosello et al., 2012; Labriet et al., 2013; Roson and van der Mensbrugghe, 2012; Tol, 2013; Dellink et al., 2014). However, it is difficult to reach a robust agreement on the degree of the economic impact. The estimated range of GDP change in 2100 compared with the scenario without climate change effects is approximately $-1.9 \%$ to $+0.03 \%$ across different models (Eboli et al., 2010; Bosello et al., 2012; Roson and van der Mensbrugghe, 2012; Dellink et al., 2014). For example, the Climate Framework for Uncertainty, Negotiation and Distribution (FUND) (Tol, 2013) shows that the annual energy savings attained from decreases in space heating demand was almost $0.4 \%$ of GDP at the end of the twentieth century, but this gain would create a substantial negative economic impact by the end of the twenty-first century (approximately $-1.9 \%$ of GDP in 2100 ). The other studies tend to show little change in GDP.

Despite the findings from previous research, further assessment of the economic impact of climate change on energy demand for space heating and cooling is needed. First, previous studies have not considered the level of uncertainty surrounding climate change associated with specific emission scenarios (Meehl et al., 2007; Taylor et al., 2011). In particular, scenarios in which $\mathrm{CO}_{2}$ is stabilized at low concentration levels so that the temperature increase is less than $2^{\circ} \mathrm{C}$ by 2100 (van Vuuren et al., 2011b) have not been included in these analyses. Such uncertainty could be integrated using the latest climate data available from the Coupled Model Intercomparison Project, Phase 5 (CMIP5) (Hempel et al., 2013). Second, previous studies were based on an aggregated relationship between average temperatures and energy consumption that only acknowledged energy changes (for example, De Cian et al., 2013) and did not incorporate stock changes in air-conditioning technology and the associated costs, even though these changes have an economic impact. Therefore, the extant methodology could be improved using a more precise model.
This study determines the economic impact caused by changes in energy demand for space heating and cooling under a wide range of climate change scenarios, including the stringent climate-mitigation scenario. In our analysis, we consider detailed technological information, such as stock changes in airconditioning technologies and their associated costs over time.

\section{Methods}

Overview. A scenario analysis was executed using an economic model (AsiaPacific Integrated Model/Computable General Equilibrium (AIM/CGE)) coupled with an end-use model (Fujimori et al., 2012) that separates the world into 17 regions (Supplementary Table 1). This approach integrates detailed information regarding energy end-use technologies, such as stock changes in air-conditioning technologies over time and their associated costs (Fujimori et al., 2014c), whereas the conventional method only incorporates aggregated energy demand. In this analysis, heating and cooling degree days (HDD and CDD, respectively) are utilized. The HDD and CDD refer to the sum of positive or negative deviations in the actual temperature from the base temperature over a given period of time. The base temperature is defined as the temperature level where there is no need for either heating or cooling (Mideksa and Kallbekken, 2010). Following Isaac and van Vuuren (2009), we used $18^{\circ} \mathrm{C}$ as the base temperature, although this criterion differs by region and over different periods of time. Changes in HDD and CDD corresponding to temperature changes computed at the half-degree grid cell scale were aggregated according to AIM/CGE regions using a population density map (Center for International Earth Science Information Network-CIESIN (Columbia University) and Centro Internacional de Agricultura Tropical-CIAT, 2005) as a weighting parameter. These values were then fed into the economic model as drivers of the associated energy consumption. The energy service demands for space heating and cooling were determined for HDD and CDD using the method from Schipper and Meyers (1992), while other energy service demands were determined using the method from Fujimori et al. (2014c).

The AIM/CGE model. The AIM/CGE model is a 1-year-step, recursive, dynamic CGE model combined with the AIM/End-use model, which is an energy end-use model based on previous work (Fujimori et al., 2012; Fujimori et al., 2014c) Supply, demand and international trade are represented across 17 regions. The production sectors maximize profits under multi-nested constant elasticity substitution (CES) functions and individual input prices. There are several powergeneration sectors, and the output of power generation from several energy sources was combined with a logit function. This method was adopted to account for the energy balance, as the CES function does not guarantee a material balance. Household expenditures with respect to each commodity are described by a linear expenditure system (LES) function. The parameters adopted in the LES function were recursively updated in accordance with income elasticity assumptions. The savings ratio was endogenously determined to balance savings and investment, and capital formation for each good was determined by a fixed coefficient. The Armington assumption was used for trade, and the current account is assumed to be balanced. Land use is determined by the logit function (Fujimori et al., 2014a; see Fujimori et al., 2012 for details of the model structure and mathematical formulas).

When considering the selection of end-use technologies and stock changes with respect to space heating and cooling demand, we assume that the household and commercial sectors require several energy services (heating, cooling, cooking, lighting and so on) and a variety of technologies to meet demand. We also assume that there are many technologies with different levels of energy efficiency that use different energy sources (for example, gas- or electric-powered vehicles) (listed in Supplementary Table 2). The selection of the exact energy technology is represented as the distribution of the share of all energy technologies with a logit function. One determinant of the share of energy technology is its overall cost, including the investment cost, the operational costs and management costs. The investments and technology costs are annualized according to specified discount rates and device lifespans. The logit selection has two parameters: price elasticity for the cost of each technology; and a basic share related to consumer preferences, inertia, and behavioural and cultural aspects. All the technological information was taken from the AIM/End-use database (Akashi and Hanaoka, 2012).

Energy service demand. The energy service demand for space heating and cooling was determined using the method from Schipper and Meyers (1992). The energy service demand for household heating and cooling was calculated as the product of population, floor area per capita, heating and cooling demand per area, and the device penetration ratio. The floor area per capita was formulated as a function of income (McNeil and Letschert, 2008), while the device penetration ratio was formulated as a function of income and CDD (Isaac and van Vuuren, 2009). For the commercial sector, demand was calculated as the product of labour population, the ratio of service sector employment, floor area per employee, demand for heating and cooling per floor area, and the device penetration ratio. The ratio for service sector employment was expressed as a function of income (McNeil and Letschert, 2008). The same device penetration ratio for households 
was used for the commercial sector (see Supplementary Information for more detailed descriptions).

Scenario settings and data. We designed two groups of scenarios, as shown in Table 1. The first was a set of basic scenarios to assess the impact of climate change, and the second was designed for a sensitivity analysis. In the basic scenario group, four climate change scenarios were simulated by incorporating four Representative Concentration Pathways (van Vuuren et al., 2011a) (RCP2.6, RCP4.5, RCP6.0 and RCP8.5) representing future climate conditions in addition to a reference scenario, which assumes that the current climate conditions persist into the future (scenario without climate change; NoCC). The economic impact (GDP gains and losses) were quantified by calculating the difference between GDP in each climate change scenario and the GDP in the NoCC. Furthermore, to measure climatic uncertainty, we used climate data estimated by five General Circulation Models (GCMs) obtained from the CMIP5 (Hempel et al., 2013) and five GCMs (Supplementary Table 3) following Hasegawa et al. (2016). Population and GDP projections for the "middle of the road" scenario (SSP2) (IIASA, 2012), which are included in the Shared Socioeconomic Pathways (SSPs) from O'Neill et al. (2014), were utilized for all scenarios. The SSPs are an interdisciplinary scenario framework designed for climate change research. They are a set of future global development trajectories that focus on specific components of socioeconomic circumstances. It should be noted that the climate change scenarios assumed here do not explicitly consider mitigation efforts, such as carbon pricing. ${ }^{1}$

The model's outputs depend on a large number of uncertain parameters. The second set of scenarios was included to analyse the model's sensitivity to parameters that are strongly related to heating and cooling demand. As indicated in Table 2, we analysed the impact of three different parameter changes: (1) population and income; (2) price elasticity of technology selection; and

\section{Table 1 | List of scenarios and their assumptions}

\begin{tabular}{|c|c|c|c|c|}
\hline Scenario & $\begin{array}{l}\text { Climatic } \\
\text { conditions }\end{array}$ & $\begin{array}{l}\text { Population } \\
\text { and } \\
\text { income }\end{array}$ & $\begin{array}{l}\text { Price elasticity of } \\
\text { technology } \\
\text { selection }\end{array}$ & $\begin{array}{l}\text { Technology } \\
\text { costs }\end{array}$ \\
\hline \multicolumn{5}{|c|}{ Base scenario } \\
\hline NoCC & Fixed & \multirow{5}{*}{ SSP2 } & \multirow{5}{*}{ middle } & \multirow{5}{*}{ middle } \\
\hline $\mathrm{RCP} 2.6$ & RCP2.6 & & & \\
\hline $\mathrm{RCP} 4.5$ & $\mathrm{RCP} 4.5$ & & & \\
\hline RCP6.0 & RCP6.0 & & & \\
\hline RCP8.5 & RCP8.5 & & & \\
\hline \multicolumn{5}{|c|}{ Sensitivity analysis for RCP8.5 } \\
\hline SSP1 & \multirow{6}{*}{ RCP8.5 } & SSP1 & \multirow{2}{*}{ middle } & \multirow{4}{*}{ middle } \\
\hline SSP3 & & SSP3 & & \\
\hline High elasticity & & \multirow{4}{*}{ SSP2 } & high & \\
\hline Low elasticity & & & low & \\
\hline High cost & & & \multirow{2}{*}{ middle } & high \\
\hline Low cost & & & & low \\
\hline
\end{tabular}

Note: There are two sets of scenarios, namely, base and sensitivity cases. Climatic conditions, demographics and income, price elasticities of technological selection, and technology costs are differentiated across scenarios.
(3) technology costs. The three parameters assumed are shown in Table 2. For population and GDP, we used the assumptions from SSP1 and SSP3. SSP1 assumes low population growth and high economic development, whereas SSP3 assumes high population growth and low economic development. Because there is insufficient information, particularly for the elasticity of technology selections and costs, we simply changed the original values of relevant parameters in the model. To determine the model's response to technology costs, high and low growth ratios for the Autonomous Energy Efficiency Improvement parameter were assumed in the model. A single version of the IPSL-CM5 model (IPSL-CM5A-LR) was used as the representative climate model in the sensitivity analysis because it eventually equalled the median of five GCMs.

\section{Results}

Total global impact. Figure 1 shows the global changes in GDP associated with changes in energy demand for space heating and cooling under different climatic conditions. The impact on GDP in the first half of the twenty-first century was close to (but less than) 0 under all climatic conditions, but it became more negative in the latter half of the century. The median negative impact on GDP in 2100 was $-0.34 \%(-0.39 \%$ to $-0.18 \%)$ for RCP 8.5 , where the temperature increase was most severe (Supplementary Fig. 8), whereas the change in GDP for RCP2.6 remained low throughout the century at $-0.03 \%(-0.07 \%$ to $-0.01 \%)$ in 2100 . For RCP 4.5 and RCP6.0, the changes in GDP and the changes in global mean temperature were between those observed in RCP2.6 and RCP8.5. GDP losses for RCP4.5 and RCP6.0 in 2100 were $-0.10 \%(-0.16 \%$ to $-0.03 \%)$ and $-0.13 \%(-0.18 \%$ to $-0.06 \%)$, respectively. The range of uncertainty across the GCMs widened as the impact increased. This tendency was most pronounced in RCP8.5, where the uncertainty in 2050 and 2100 was $0.06 \%$ and $0.21 \%$, respectively. GDP losses decreased in the last 5 years of the model because they are primarily driven by increases in air conditioner ownership, which becomes saturated by the end of the century, while GDP steadily increases.

Changes in space heating and cooling demand. To provide an overview and a regional perspective of HDD and CDD changes, Fig. 2 shows HDD and CDD for RCP2.6 and RCP8.5 globally and across five regions (see Supplementary Fig. 7 for RCP4.5 and RCP6.0). Future temperature increases are projected to reduce HDD and increase CDD in all scenarios, although the size of the temperature increase is different across regions. The increase in CDD was much larger than the decrease in HDD at the global level. In addition, the changes in both HDD and CDD were greater in RCP8.5 than in RCP2.6 across all regions.

In terms of regional heterogeneity, different trends were present in warmer versus cooler climates (Fig. 2). Relatively warm regions, such as Asia (ASIA), Latin America (LAM) and the Middle East/Africa (MAF), had a high CDD in the base year, while the OECD countries (OECD90) and the Reforming Economies (REF), which are generally located in cooler climate

\section{Table 2 | Parameters changed in the sensitivity analysis}

\begin{tabular}{ll} 
Scenario & Parameters and alternative values chosen \\
\hline SSP1 & The SSP1 scenario assumes low population growth and high economic growth \\
SSP3 & The SSP3 scenario assumes high population growth and low economic growth \\
High elasticity & A scenario that incorporates a shift from an original parameter representing technology selection price elasticity (-5.0) in a logit \\
function to a higher elasticity parameter ( -7.0$)$
\end{tabular}




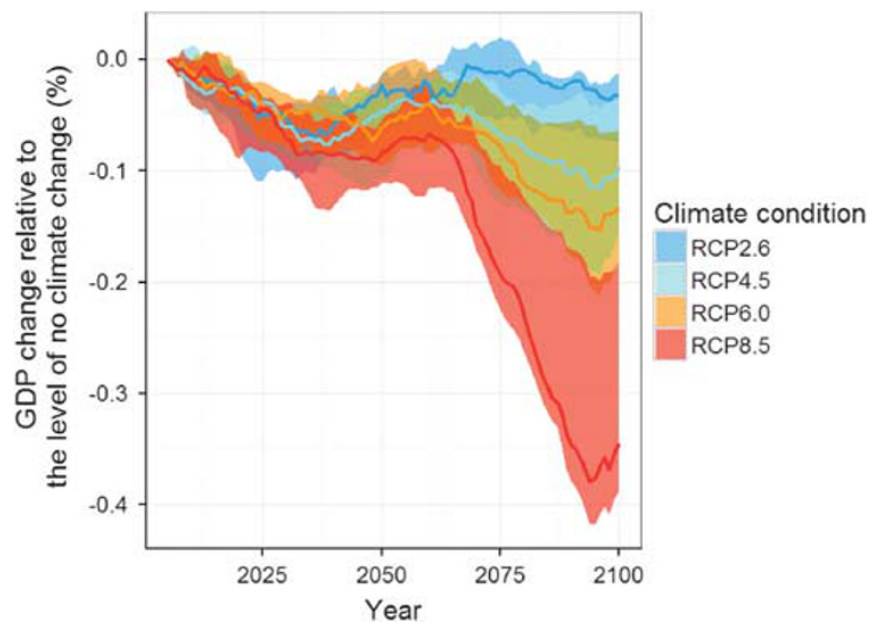

Figure 1 | Changes in global GDP due to changes in demand for space heating and cooling under different climatic conditions.

Note: GDP changes are shown as changes from the level without any climate change. The lines show the median values, and the ranges represent the uncertainty ranges of the GCMs. See Supplementary Fig. 6 for regional breakdown. zones, had a low CDD. The regional deviations from the base year levels differed, with future climate change projected to produce a large decrease in HDD in the cooler regions. In contrast, the warmer regions were not expected to experience a large decrease in HDD in RCP8.5 because they are already warm. The trends for CDD were almost the opposite of those for HDD, with warmer regions having a high CDD in the base year, and there was a large temperature increase in RCP8.5. The global result followed a trend similar to the warmer regions (ASIA, LAM and MAF) because the gridded information for HDD and CDD was aggregated at the global or regional levels using a population density map, and most of the global population is found in these regions.

The uncertainty range associated with the climate models widened as the absolute values of HDD and CDD increased across all regions (Fig. 2). The uncertainty range increased over time; for example, 2100 was more uncertain than 2050, and 2050 was more uncertain than the base year. The uncertainty range of HDD in the OECD and REF was large, whereas it was smaller for the other regions. The opposite trend applied to CDD, as RCP8.5 had a larger uncertainty range than RCP2.6.

Regional economic impacts. Climate change affects energy demand in opposite directions through changes in HDD and
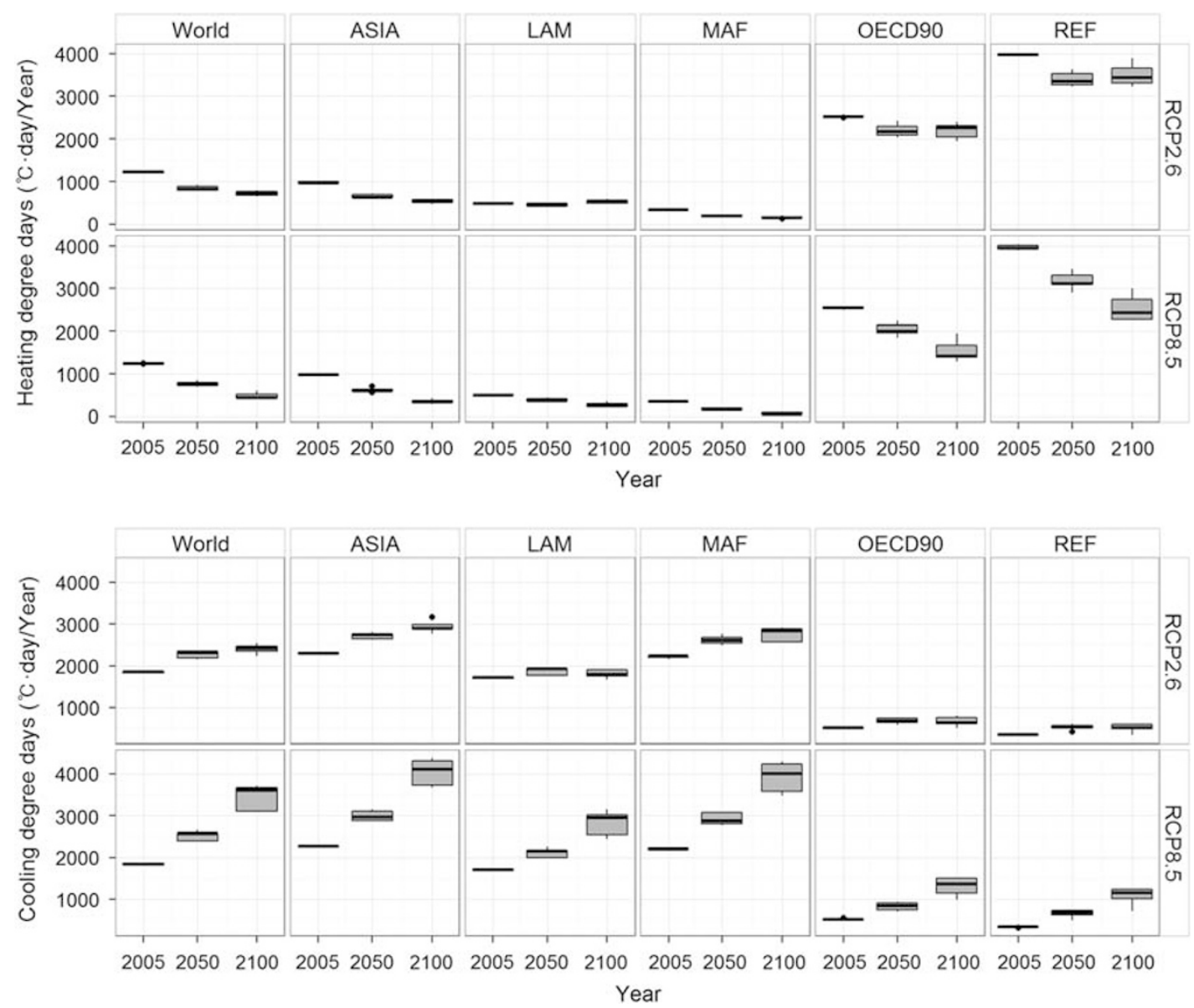

Figure 2 | Heating (top) and cooling (bottom) degree days for the low and high greenhouse gas emission scenarios (RCP2.6 and RCP8.5) at the global level and across five regions.

Note: Boxes and lines represent the uncertainty ranges across the five GCMs. Boxes represent the first-third quartile range and the plain line indicates the median (ASIA: Asia except OECD90 countries; MAF: Middle East and Africa; LAM: Latin America; OECD90: United Nations Framework Convention on Climate Change [UNFCCC] Annex I countries; REF: Eastern Europe and Former Soviet Union). See Supplementary Material for details on RCP4.5 and RCP6.0. 


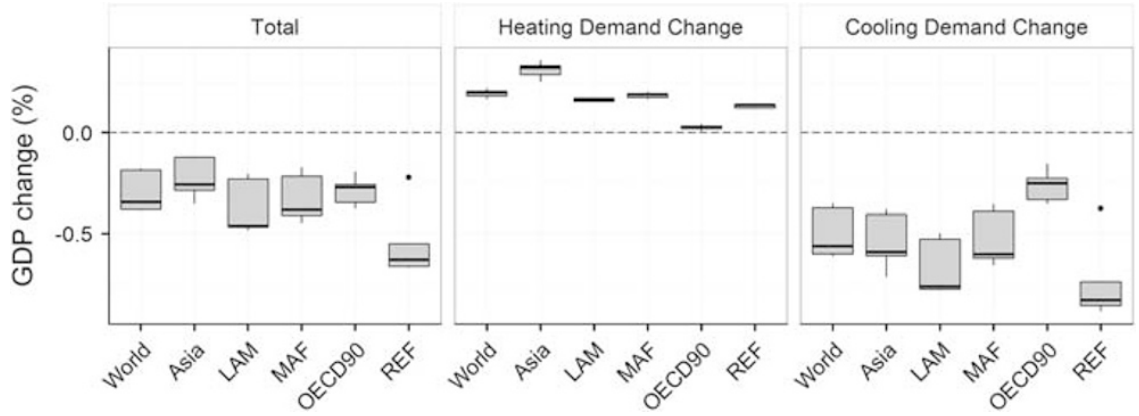

Figure 3 | GDP changes in 2100 and RCP8.5 (relative to the scenario without climate change) due to changes in the demand for energy services for heating (HDD) and cooling (CDD) degree days at the global and regional levels.

Note: "Total" considers the changes in both HDD and CDD, while the other two cases only consider changes in either HDD or CDD, respectively. Boxes and lines show the uncertainty range across the five GCMs. Boxes represent the first-third quartile range and the plain line indicates the median. See Fig. 2 for regional codes.

CDD. A decrease in HDD encourages energy savings, while an increase in CDD drives an increase in energy demand. However, this does not necessarily mean that regions with a cooler climate, where the decrease in HDD is much larger than the increase in $\mathrm{CDD}$, would benefit economically from a decrease in energy demand while warmer regions would experience an economic loss. To determine the economics of the changes in HDD and $\mathrm{CDD}$, the economic impacts were deconstructed into the effects of regional changes in HDD and CDD.

Figure 3 shows the projected GDP change in 2100 deconstructed into the economic effects of HDD and CDD for RCP8.5. The "Total" case considers changes in both HDD and CDD, while the other two cases only consider changes in either HDD or CDD. It is clear that HDD changes have a positive effect and CDD changes have a negative effect on GDP. The total economic effects are negative because the negative effects of $\mathrm{CDD}$ are much greater than the positive effects of HDD. The effects of HDD and CDD on the global total are $+0.2 \%$ and $-0.6 \%$ (median values) of GDP, respectively. These results are consistent with the initial assumption that energy demand for space cooling increases with an increase in the device's penetration ratio along with an increase in the temperature.

The effects of changes in HDD and CDD differ across regions. Of the five regions, REF had the highest loss in GDP of $-0.7 \%$ (median) in 2100 , even though it showed a small increase in CDD (Fig. 2). This result occurred because REF has relatively high energy expenditures within its regional economy and it tends to experience large economic impacts associated with structural changes in the energy sector. Similar phenomena have also been observed in mitigation studies (Fujimori et al., 2014b). LAM showed the second greatest loss in GDP. This loss in GDP is due to an increase in CDD because the device penetration ratio in the LAM region is currently low, but will increase in response to income growth and rising temperatures. In contrast, ASIA showed a relatively small decrease in GDP, even though it demonstrated a large increase in CDD (Fig. 2). Finally, OECD90 experienced a small loss in GDP due to a small reduction in CDD because the countries in this region already have a high device penetration ratio in terms of cooling devices and this ratio will not increase in the future, even if CDD increases.

Sources of economic loss. ${ }^{2}$ We examined the incremental costs of using heating and cooling technologies (most of which are air conditioners) as a main factor generating GDP loss. Figure 4 shows the GDP loss, the additional costs for introducing heating

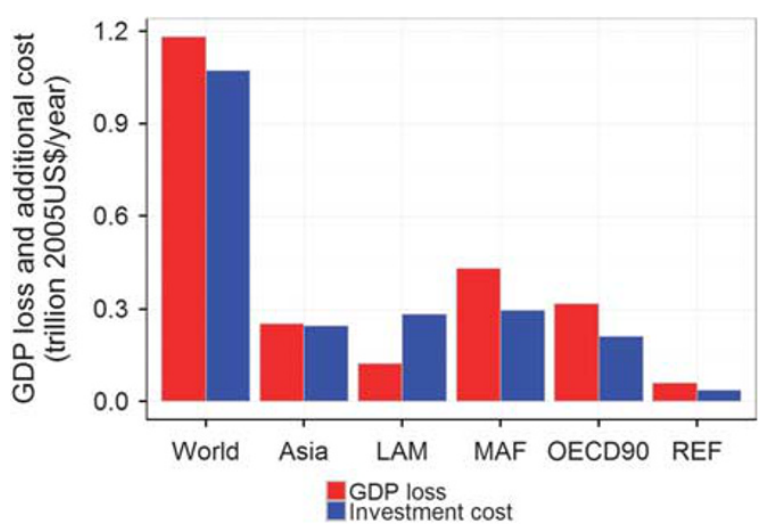

Figure 4 | GDP loss and additional investment cost for introducing heating and cooling technology in RCP8.5 worldwide and in five regions compared with the case without climate change (NoCC) in 2100. Note: The values represent the median across five climate models (GCM is IPSL-CM5A-LR). See Fig. 2 for regional codes.

and cooling technologies and their energy use in RCP8.5 compared with the NoCC scenario at the global level and against the five regional categories in 2100 (see Supplementary Fig. 11 for global and regional energy use in RCP8.5). Overall, the loss in GDP can be explained by the incremental costs for investments in technology and energy use. For example, the global GDP loss was about US $\$ 1.2$ trillion, whereas the additional cost was $\$ 1.1$ trillion. These two indicators are consistent for all regions, except LAM, where they are comparable but slightly larger than those for the other regions. This situation could be a result of the general equilibrium effect and changes in the price of energy. However, from our analysis, we can clearly see that the additional technology and energy costs are strongly related to GDP loss.

Sensitivity analysis. We also analysed the impact of various model parameters. As illustrated in Fig. 5, the results of the sensitivity analysis indicate that the amount of economic loss can vary substantially based on model inputs. Economic loss is influenced primarily by assumptions of technological costs, population and income levels. Technology costs are projected to cause an approximate $-0.5 \%$ to $0.0 \%$ decline in global GDP by 2100. This range is wider than that previous estimates found by 
multiple climate models. However, this does not necessarily mean that the technological costs are more uncertain than those found in other climatic conditions, as we simply altered the parameters to ascertain the model's sensitivity. This suggests that assumptions regarding technology costs could significantly change the results and should be carefully set using the richer data possible.

Population and income influenced economic impact from $-0.2 \%$ to $0 .-0 \%$ at the global level. GDP losses for both SSP1 and SSP3 were smaller compared with the reference case. In SSP1, which assumes a high level of economic development, the income increase led to a higher device penetration ratio compared with the reference case; thus, the costs related to incremental cooling demand are high. However, GDP is actually higher in SSP1 than in the reference case; therefore, the GDP loss rate is lower than the reference case. In contrast, SSP3, which assumes low economic development, shows smaller GDP losses than those in the reference case due to a lower device penetration ratio. It can therefore be said that different socioeconomic scenarios affect the results. The income assumption, which significantly affects the device penetration ratio, is also an important consideration.

Comparison with earlier studies and the implications of this study. Although several earlier studies investigated economic losses caused by changes in energy demand under climate change, there is no agreement about the extent of these losses. Some studies indicated that the losses would be more than $1.0 \%$, while

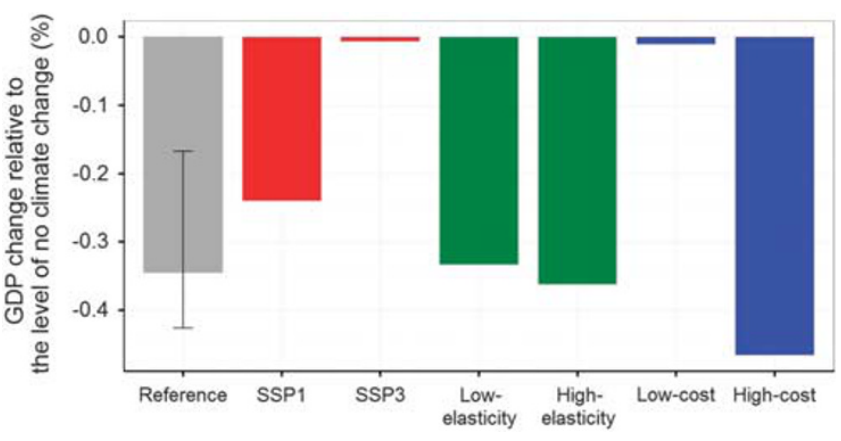

Figure 5 | Sensitivity analyses show the global economic loss caused by the changes in energy demand in 2100 for RCP8.5 in different scenarios considering three uncertain parameters: (1) population and income; (2) price elasticity of the technology selection; and (3) technology costs. Note: The reference value represents the median value (GCM is IPSLCM5A-LR) and the black line shows the range of five climate models. See Table 1 for scenario definitions. See Supplementary Figs. 9 and 10 for regional breakdown. other studies suggested lower losses, as shown in Table 3. It is difficult to evaluate the validity of these studies because they adopted different time frames, climatic conditions and socioeconomic factors. However, we can discuss two aspects of these studies here. First, earlier studies using the CGE model did not explicitly consider demand for space heating and cooling, whereas our study integrates this demand. Furthermore, we explicitly incorporated energy technologies and energy services in detail. As shown above, the economic losses were mainly generated by incremental technological costs and not by changes in energy demand itself. This indicates that earlier studies that did not consider device costs could have underestimated the economic losses because they only included energy demand. The FUND (Tol, 2013) referred to these outdated sources to determine their damage function without considering any device costs. However, they showed larger economic losses than those identified in previous studies. We could not identify the factors affecting their results. In conclusion, we believe our study provides new, more precise insights with respect to the economic consequences of energy demand changes associated with future climate change.

Regarding energy demand in terms of physical volume, several studies have reported changes in energy demand (rather than economic impact). The percentage increase in energy demand in this study is comparable with the estimates of Isaac and van Vuuren (2009), although the socioeconomic factors, climatic conditions and sector coverage ${ }^{3}$ are different. Isaac and van Vuuren (2009) projected the global demand for energy during the twenty-first century and found that energy demand for space heating gradually rose until 2030 and then stabilized, while energy demand for cooling continued to increase until 2100. They also showed in their reference scenario that demand for energy increased incrementally by about 4 EJ/year (about $5 \%$ of the total energy demand) in 2100 through the use of a scenario in which $\mathrm{CO}_{2}$ concentration is stabilized at $450 \mathrm{ppm}$. In a rough mapping exercise, their reference scenario corresponded to RCP8.5 in our study, and their scenario in which $\mathrm{CO}_{2}$ concentration stabilized at $450 \mathrm{ppm}$ corresponded to RCP2.6. In RCP8.5, the change in energy demand due to climate change ranged from +15.0 to +44.8 $\mathrm{EJ} /$ year in 2100 (equivalent to $+5.1 \%$ to $+15.2 \%$ of the total energy demand). De Cian et al. (2013) attempted to determine the changes in energy consumption associated with climate change in the OECD regions ${ }^{4}$ in 2085 using an econometric analysis. They indicated that the change in total energy demand in these regions was about $40 \mathrm{EJ} / \mathrm{year}$. Because energy consumption in the absence of climate change was not determined in their study, it is difficult to compare their results with ours. Nevertheless, they also found an increased demand in energy.

Limitations and uncertainty. There are several limitations in our study. First, we used $18^{\circ} \mathrm{C}$ as the base temperature for HDD and CDD by referring to Isaac and van Vuuren (2009). Any change in

Table 3 | List of earlier studies relevant to global economic losses due to changes in energy demand associated with climate change (relative to the scenario without climate change)

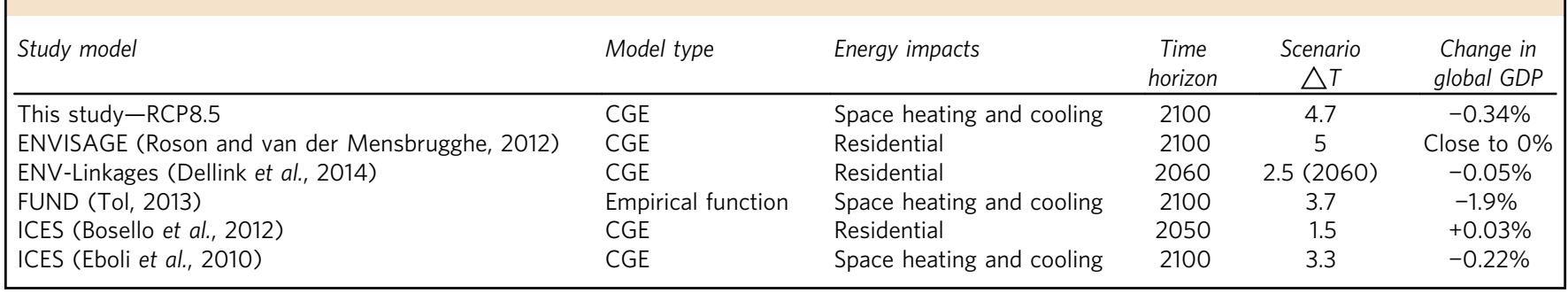


this value could alter the magnitude of the economic losses, but the trends and extent of our main findings would not change significantly. Second, it would be interesting to further consider mitigation policies, which are not incorporated in this study but are obviously required for mitigation scenarios. If the price of carbon was included in our analysis, as it often is in mitigation scenarios, we could estimate the economic losses more precisely. However, according to our RCP2.6 scenario, the effect of changes in HDD and CDD was small. Conventional mitigation measures, such as better power systems and other technological innovations, seem to be more important than changes in HDD and CDD. With respect to the RCP4.5 and RCP6.0 scenarios, the situation is slightly different. For these stabilization scenarios, the price of carbon is not as high, so the mitigation effect would not be as large. Instead, socioeconomic variables are expected to be the primary factors. Finally, we did not consider health impacts due to heat stress from extreme heat waves. Such issues are beyond the scope of this study, but they should be considered in future work.

\section{Conclusions}

We quantified the economic impact of changes in energy demand for space heating and cooling under climate change scenarios using an economic model. In our analysis, we considered the uncertainty of future climatic conditions using the latest climate information from CMIP5. Furthermore, we explicitly treated the device penetration ratio of energy-consuming technologies for space heating and cooling by incorporating a bottom-up, end-use approach in the CGE model and then calculating the incremental investment cost and energy demand when introducing these technologies based on stock changes. This factor strongly influences the economic impact, but it was not previously considered in earlier studies. We also performed a sensitivity analysis to identify the effects of various model parameters that determine the magnitude of the economic impact. In summary, we found the following results:

(1) The negative impacts of increases in the demand for space cooling on the economy were large enough to neutralize the positive impacts of decreases in space heating demand under climate change scenarios, leading to significant economic loss. The economic impact due to changes in demand for space heating and cooling would result in a $-0.34 \%(-0.39 \%$ to $-0.18 \%$ ) change in global GDP by the end of the twentyfirst century in the highest emissions scenario (RCP8.5), compared with the scenario without any climate change. In contrast, the impact would equal a $-0.03 \%(-0.07 \%$ to $-0.01 \%)$ change in GDP in the lowest emissions scenario (RCP2.6). The stabilization of $\mathrm{CO}_{2}$ concentrations aimed at $2^{\circ} \mathrm{C}$ (RCP2.6) corresponds to an approximate $0.31 \%$ increase in global GDP from the levels in RCP8.5.

(2) Economic loss is mainly caused by incremental technology costs for space cooling and socioeconomic changes, such as increases in population and income. More specifically, an income increase in low-income countries augments the climate change impact by increasing the device penetration ratio and technological costs. The amount of economic loss can vary substantially based on assumptions of technological costs and socioeconomic changes. To reduce the negative impacts of climate change, measures for reducing the costs of air conditioners will be important.

\section{Notes}

1 Some readers may be concerned about consistency in the scenario for SSP2 and RCP8.5. We calculated a radiate forcing for SSP2 using a simple climate model, MAGICC
(Model for the Assessment of Greenhouse Gas Induced Climate Change) (Meinshausen et al., 2011), and found that the forcing is approximately $7.3 \mathrm{~W} / \mathrm{m}^{2}$ in 2100 . Considering climate internal variability and multi-climate model uncertainty, we determined that the difference from $8.5 \mathrm{~W} / \mathrm{m}^{2}$ is acceptable.

2 It may be assumed that additional energy expenditure and technological costs associated with climate change would increase GDP. However, there could be positive and negative effects, and the exact situation is uncertain without conducting various simulations. At the household level, the additional costs stimulate activity in the energy-related industries. If productivity (labour and capital) in the energy-related sectors is higher than in the other sectors, such additional expenditures could have a positive effect on the macroeconomy. However, sectoral productivities and the household sector's consumption of goods in response to climate change are unknown, and therefore the final outcome remains unknown without further simulations. If the commercial sector requires additional expenditures for energy and space-cooling technologies, there will be a negative impact on the macroeconomy because these incremental expenditures are intermediate inputs that do not contribute to household welfare or GDP.

3 This study deals with commercial and residential sectors, whereas Isaac and van Vuuren (2009) only considered residential sectors.

4 India, Indonesia, Thailand and Venezuela are also included.

\section{References}

Akashi O and Hanaoka T (2012) Technological feasibility and costs of achieving a $50 \%$ reduction of global GHG emissions by 2050: Mid- and long-term perspectives. Sustainability Science; 7 (2): 139-156.

Arent DJ et al (2014) Key economic sectors and services. In: Field CB et al. (eds). Climate Change 2014: Impacts, Adaptation, and Vulnerability. Part A: Global and Sectoral Aspects. Contribution of Working Group II to the Fifth Assessment Report of the Intergovernmental Panel of Climate Change. Cambridge University Press: Cambridge, UK and New York.

Bosello F, Eboli F, Pierfederici R (2012) Assessing the economic impacts of climate change: An uploaded CGE point of view. In: Carraro C (ed). Nota di Lavoro. Fondazione Eni Enrico Mattei: Milano, Italy.

Center for International Earth Science Information Network-CIESIN (Columbia University) and Centro Internacional de Agricultura Tropical-CIAT. (2005) Gridded Population of the World, Version 3 (GPWv3): Population Density Grid. NASA Socioeconomic Data and Applications Center (SEDAC): Palisades, NY.

Ciscar J-C and Dowling P (2014) Integrated assessment of climate impacts and adaptation in the energy sector. Energy Economics; 46, 531-538.

De Cian E, Lanzi E and Roson R (2013) Seasonal temperature variations and energy demand. Climatic Change; 116 (3): 805-825.

Dellink R, Lanzi E, Chateau J, Bosello F, Parrado R and De Bruin KC (2014) Consequences of Climate Change Damages for Economic Growth a Dynamic Quantitative Assessment. OECD Economics Department Working Paper. OECD Publishing: Paris, France.

Eboli E, Parrado R and Roson R (2010) Climate-change feedback on economic growth: Explorations with a dynamic general equilibrium model. Environment and Development Economics; 15 (5): 515-533.

Eom J, Clarke L, Kim SH, Kyle P and Patel P (2012) China's building energy demand: Long-term implications from a detailed assessment. Energy; 46 (1): 405-419.

Fujimori S, Masui T and Matsuoka Y (2012) AIM/CGE [basic] manual. Discussion Paper Series. Center for Social and Environmental Systems Research, NIES: Tsukuba, Japan.

Fujimori S, Hasegawa T, Masui T and Takahashi K (2014a) Land use representation in a global CGE model for long-term simulation: CET vs. logit functions. Food Security; 6 (5): 685-699.

Fujimori S, Kainuma M, Masui T, Hasegawa T and Dai H (2014b) The effectiveness of energy service demand reduction: A scenario analysis of global climate change mitigation. Energy Policy; 75, 379-391.

Fujimori S, Masui T and Matsuoka Y (2014c) Development of a global computable general equilibrium model coupled with detailed energy end-use technology. Applied Energy; 128 (1): 296-306.

Hasegawa T, Fujimori S, Takahashi K, Yokohata T and Masui T (2016) Economic implications of climate change impacts on human health through undernourishment. Climatic Change, doi: 10.1007/s10584-016-1606-4.

Hempel S, Frieler K, Warszawski L, Schewe J and Piontek F (2013) A trendpreserving bias correction-The ISI-MIP approach. Earth System Dynamics Discuss; 4 (1): 49-92.

IIASA. (2012) Shared Socioeconomic Pathways (SSP) Database Version 0.9.3. Available at: https://tntcat.iiasa.ac.at/SspDb.

Isaac $M$ and van Vuuren DP (2009) Modeling global residential sector energy demand for heating and air conditioning in the context of climate change. Energy Policy; 37 (2): 507-521.

Labriet $\mathrm{M}$ et al (2013) Worldwide impacts of climate change on energy for heating and cooling. Mitigation and Adaptation Strategies for Global Change; 20 (7): 1111-1136. 
McNeil MA and Letschert VE (2008) Future Air Conditioning Energy Consumption in Developing Countries and what can be done about it: The Potential of Efficiency in the Residential Sector. Lawrence Berkeley National Laboratory. Retrieved from: http://escholarship.org/uc/item/64f9r6wr.

Meehl GA et al (2007) The WCRP CMIP3 Multimodel dataset: A new era in climate change research. Bulletin of the American Meteorological Society; 88 (9): 1383-1394.

Meinshausen M, Raper S and Wigley T (2011) Emulating coupled atmosphereocean and carbon cycle models with a simpler model, MAGICC6-Part 1: Model description and calibration. Atmospheric Chemistry and Physics; 11 (4): 1417-1456.

Mideksa TK and Kallbekken S (2010) The impact of climate change on the electricity market: A review. Energy Policy; 38 (7): 3579-3585.

Mima S and Criqui P (2009) Assessment of the impacts under future climate change on the energy systems with the POLES model. International Energy Workshop. Venise, Italy.

O'Neill B et al (2014) A new scenario framework for climate change research: The concept of shared socioeconomic pathways. Climatic Change; 122 (3): 387-400.

Roson R and van der Mensbrugghe D (2012) Climate change and economic growth: Impacts and interactions. International Journal of Sustainable Economy; 4 (3): 270-285.

Schipper L and Meyers S (1992) Energy Efficiency and Human Activity. Cambridge University Press: Cambridge, UK.

Taylor KE, Stouffer RJ and Meehl GA (2011) An overview of CMIP5 and the experiment design. Bulletin of the American Meteorological Society; 93 (4): 485-498.

Tol RJ (2013) The economic impact of climate change in the 20th and 21st centuries. Climatic Change; 117 (4): 795-808.

van Vuuren DP et al (2011a) The representative concentration pathways: An overview. Climatic Change; 109 (1-2): 5-31.

van Vuuren DP et al (2011b) RCP2.6: Exploring the possibility to keep global mean temperature increase below $2^{\circ} \mathrm{C}$. Climatic Change; 109 (1): 95-116.

Zhou Y et al (2014) Modeling the effect of climate change on U.S. state-level buildings energy demands in an integrated assessment framework. Applied Energy; 113, 1077-1088.

\section{Data Availability}

The datasets generated during this study are available in the Dataverse repository: http:// dx.doi.org/10.7910/DVN/4CSENJ.

\section{Author Contributions}

Author contributions: TH, CP and SF designed the research; CP and SF carried out the research, using an economic model and climate data; $\mathrm{TH}, \mathrm{CP}$ and SF wrote the article. All authors contributed to the analysis and discussion of the results.

\section{Acknowledgements}

This work was supported by the Environment Research and Technology Development Fund of the Ministry of the Environment of Japan, the Integrated Climate AssessmentRisks, Uncertainties and Society (ICA-RUS) (S10), and the Research on the development of an integrated assessment model incorporating global-scale climate change mitigation and adaptation (S-14-5).

\section{Additional Information}

Supplementary Information: accompanies this paper at http://www.palgrave-journals .com/palcomms

Competing interests: The authors declare no competing financial interests.

Reprints and permission information is available at http://www.palgrave-journals.com/ pal/authors/rights_and_permissions.html

How to cite this article: Hasegawa T (2016). Quantifying the economic impact of changes in energy demand for space heating and cooling systems under varying climatic scenarios. Palgrave Communications. 2:16013 doi: 10.1057/palcomms.2016.13.

\section{(c) (1)}

This work is licensed under a Creative Commons Attribution 4.0 International License. The images or other third party material in this article are included in the article's Creative Commons license, unless indicated otherwise in the credit line; if the material is not included under the Creative Commons license, users will need to obtain permission from the license holder to reproduce the material. To view a copy of this license, visit http://creativecommons.org/licenses/by/4.0/ 